\title{
The granzyme B-Serpinb9 axis controls the fate of lymphocytes after lysosomal stress
}

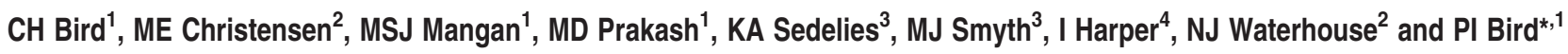

Cytotoxic lymphocytes (CLs) contain lysosome-related organelles (LROs) that perform the normal degradative functions of the lysosome, in addition to storage and release of powerful cytotoxins employed to kill virally infected or abnormal cells. Among these cytotoxins is granzyme B (GrB), a protease that has also been implicated in activation (restimulation)-induced cell death of natural killer (NK) and T cells, but the underlying mechanism and its regulation are unclear. Here we show that restimulation of previously activated human or mouse lymphocytes induces lysosomal membrane permeabilisation (LMP), followed by GrB release from LROs into the CL cytosol. The model lysosomal stressors sphingosine and Leu-Leu-methyl-ester, and CLs from gene-targeted mice were used to show that LMP releases GrB in both a time- and concentration-dependent manner, and that the liberated GrB is responsible for cell death. The endogenous GrB inhibitor Serpinb9 (Sb9) protects CLs against LMP-induced death but is decreasingly effective as the extent of LMP increases. We also used these model stressors to show that GrB is the major effector of LMP-mediated death in T cells, but that in NK cells additional effectors are released, making GrB redundant. We found that limited LMP and GrB release occurs constitutively in proliferating lymphocytes and in NK cells engaged with targets in vitro. In Ectromelia virus-infected lymph nodes, working NK cells lacking Sb9 are more susceptible to GrB-mediated death. Taken together, these data show that a basal level of LMP occurs in proliferating and activated lymphocytes, and is increased on restimulation. LMP releases GrB from LROs into the lymphocyte cytoplasm and its ensuing interaction with Sb9 dictates whether or not the cell survives. The GrB-Sb9 nexus may therefore represent an additional mechanism of limiting lymphocyte lifespan and populations.

Cell Death and Differentiation (2014) 21, 876-887; doi:10.1038/cdd.2014.7; published online 31 January 2014

Following antigen elimination, superfluous activated lymphocytes are removed to maintain lymphocyte homeostasis and avoid accumulation of autoreactive cells. One mechanism of $\mathrm{T}$-cell clearance is restimulation-induced cell death, a process dependent on restimulation of T-cell receptors (TCRs) on previously activated cells. ${ }^{1}$ Several death pathways have been implicated in restimulation-induced cell death. The best studied is the extrinsic, cell death receptor-dependent pathway, ${ }^{2}$ although death receptor-independent pathways also exist. ${ }^{3,4}$ Activated natural killer (NK) cells are also eliminated via death receptor signalling. However, in some NK cells restimulation of activating receptors such as $\mathrm{CD} 94,{ }^{5} \mathrm{CD} 2^{6}$ or CD16 $6^{5,7,8}$ results in very rapid death, independent of death receptor signalling. For simplicity, restimulation of previously activated NK and T cells via activating receptors will be referred to here as activation-induced cell death (AICD).

Emerging evidence suggests that AICD is associated with lysosomal instability within cytotoxic lymphocytes (CLs), which comprise $\mathrm{CD}^{+}{ }^{+}$cytotoxic T lymphocytes (CTLs) and NK cells. These contain specialised secretory lysosome- related organelles (LROs), ${ }^{9}$ which harbour normal lysosomal proteins, as well as perforin (Pf) and serine proteases (granzymes) housed within an unusual membrane-bound subcompartment called the dense core. ${ }^{10}$ During CL killing, LROs fuse with the plasma membrane and release their contents into the synapse. Pf and granzymes then kill the target cell. Granzyme B (GrB) is a potent cytotoxin, which behaves similar to an apical caspase; ${ }^{11,12}$ thus, CLs themselves are protected from GrB by the specific nucleocytoplasmic protease inhibitor SERPINB9 (PI-9 in humans, Serpinb9 (Sb9) or Spi-6 in the mouse, and herein abbreviated as $\mathrm{Sb9}$ for both species). ${ }^{13-17}$

Cytosolic GrB is associated with AICD of mouse and human T cells ${ }^{18-21}$ and human NK cells, ${ }^{6}$ but its source, whether it is necessary and sufficient for death in all settings and whether it induces suicide or fratricide, has yet to be established. It is proposed but not proven to originate from destabilised LROs, but when and how this might occur has not been explained. Furthermore, the possibilities that it originates from a different compartment or is first secreted then reinternalised have not

\footnotetext{
${ }^{1}$ Department of Biochemistry and Molecular Biology, School of Biomedical Sciences, Monash University, Melbourne, VIC, Australia; ${ }^{2}$ Apoptosis and Cytotoxicity Laboratory, Mater Medical Research Institute, Brisbane, QLD, Australia; ${ }^{3}$ Cancer Cell Death, Cancer Immunology Program, Peter MacCallum Cancer Centre, Melbourne, VIC, Australia and ${ }^{4}$ Monash Micro Imaging, Monash University, Melbourne, VIC, Australia

*Corresponding author: PI Bird, Department of Biochemistry and Molecular Biology, School of Biomedical Sciences, Monash University, Wellington Road, Clayton 3800 , Australia. Tel: +61 39902 9365; Fax: +61 39902 9500; E-mail: phil.bird@monash.edu

Keywords: lysosomal membrane permeabilisation; granzyme B; Serpinb9; cytotoxic lymphocytes; activation-induced cell death

Abbreviations: AICD, activation-induced cell death; AO, acridine orange; con-A, concanavalin A; CL, cytotoxic lymphocyte; CTL, cytotoxic T lymphocyte; GAM, goat anti-mouse; Gr, granzyme; LLOMe, Leu-Leu-methyl-ester; LMP, Iysosomal membrane permeabilisation; LRO, lysosome-related organelle; LSB, Laemmli sample buffer; NK, natural killer; Pf, perforin; Sb9, Serpinb9; TCR, T-cell receptor; wt, wild type

Received 24.10.12; revised 05.12.13; accepted 02.1.14; Edited by RA Knight; published online 31.1.14
} 
been ruled out. Although it is accepted that in some cells stress results in lysosomal membrane permeabilisation (LMP) and release of lysosomal contents into the cytosol causing death, ${ }^{22,23}$ whether LMP readily occurs in CLs and is connected to AICD is unknown.

Here we show for the first time that continuous or repeated stimulation of activated CLs results in LRO damage and LMP. The resulting release of $\mathrm{GrB}$ into the cytosol, if not opposed by Sb9, triggers cell death. We also demonstrate that cytosolic $\mathrm{GrB}$ arises from an intracellular pool, as cells unable to degranulate are sensitive to AICD. Furthermore, we show that GrB is a prime mediator of AICD in T cells and is important but not essential for AICD in NK cells. Finally, to place these findings in context, we examined NK cells engaged with target cells in vitro and in vivo. We observed LMP and GrB-mediated death of working NK cells. We conclude that triggering or amplifying LMP via restimulation shifts the cytosolic GrB-Sb9 balance in favour of $\mathrm{GrB}$, which may provide another means of limiting CL lifespan.

\section{Results}

GrB from LROs contributes to AICD of CTL and is controlled by Sb9. Extragranular (cytosolic) GrB has been linked to AICD of CTL. Although the compartment(s) and triggers involved are unclear, there is nevertheless an implied role for its cognate inhibitor Sb9 in the regulation of AICD. To investigate these issues, we used model systems of AICD. Human $\mathrm{CD}^{+} \mathrm{T}$ cells were activated with concanavalin-A (con-A), which binds the TCR and other mannosylated receptors. By day 3, most cells expressed $\mathrm{GrB}$, yet Sb9 expression remained constant (Figure 1a). Restimulation by a second exposure to con-A killed $\sim 50 \%$ of CTLs within $4 \mathrm{~h}$ (Figure $1 \mathrm{~b}$ ), recapitulating reported death in response to CD3 stimulation. ${ }^{19}$ Longer exposure to con-A/IL-2 had no further effect (not shown). Pretreatment with a cellpermeable specific inhibitor of human GrB (C20, ${ }^{24}$ see Figure $3 e$ ) protected a significant proportion of cells from death (Figure 1b).

As shown in Figure 1c, in activated but non-restimulated ( - con-A) cells, GrB is generally confined to LROs as defined by the lysosomal protein Lamp 1. However, in some cells GrB is apparent outside the boundaries of Lamp 1, indicating release of GrB from LROs into the cytosol, and suggesting that non-restimulated cells undergo limited LMP that does not result in death. By contrast, after con-A treatment (restimulation) the number of cells with extra-LRO GrB markedly increased, with some showing both cytosolic and nuclear material, consistent with previous reports of GrB accumulation in nuclei of damaged cells (Figure 1c). ${ }^{25}$ Quantitative colocalisation analysis confirmed reduced overlap of GrB staining with Lamp 1 in response to increasing concentrations of con-A (Figure 1d). Given these cells were pretreated with nocodazole (an inhibitor of microtubules) to prevent loss of GrB via exocytosis, we conclude that the cytosolic GrB is indeed derived from within the cell, thus linking receptor restimulation to LRO damage.

To examine the contribution of GrB or other LRO proteins, and the role of Sb9 in AICD, we analysed splenocytes from mice lacking $\mathrm{GrB}, \mathrm{Sb9}$, or both. Before restimulation $\sim 80 \%$ of splenocytes were T cells, and wild-type (wt) and Sb9-null cells expressed similar levels of LRO-associated GrB (Supplementary Figures $1 \mathrm{a}$ and $\mathrm{b}$ ). Restimulation with con-A (Figure $2 \mathrm{a}$ ) killed $\sim 80 \%$ of the wt population, but within $48 \mathrm{~h}$ the population recovered due to the mitogenic effect of con-A. Lymphocytes lacking GrB showed enhanced survival after $24 \mathrm{~h}$ and expanded much more quickly compared with wt lymphocytes. By contrast, Sb9-null cells were more sensitive to con-A restimulation and expanded more slowly than wt. Finally, GrB/Sb9 double-null splenocytes resembled GrB-null splenocytes. These data are consistent with a proposed role for GrB in AICD and indicate that the GrB-Sb9 interplay modulates AICD in T cells. The differences in re-expansion rates also indicate that LMP and GrB release normally occurs in proliferating cells. The $\mathrm{GrB} / \mathrm{Sb} 9$ nexus also modulates death in activated splenocytes specifically restimulated via the TCR using plate-bound anti-CD3 (Figure 2b). Here, more wt cells survived restimulation compared with con-A treatment, but the survival of GrB-null or Sb9-null cells was similar in both settings. This suggests that con-A is a stronger inducer of LMP than anti-CD3, releasing larger amounts of GrB. Importantly, cells from each genotype divided at the same rate post-restimulation, indicating that differences in cell number are due to increased cell death rather than differing proliferation rates (Figure $2 \mathrm{c}$ ).

To eliminate the possibility that cytosolic GrB is derived from secreted then re-internalised $\mathrm{GrB}$, or transfer of $\mathrm{GrB}$ from one $C L$ to another (fratricide), we studied activated splenocytes from fusion-incompetent Jinx mice (Figure 2d). The response of these cells to con-A restimulation was similar to wt (not shown). As seen in human T cells, GrB in activated but not restimulated Jinx cells is essentially confined to vesicles defined by Lamp 1, although individual LROs showing GrB staining just outside the LRO periphery were evident in some cells (Figure 2d). By contrast, extralysosomal cytosolic GrB was readily detected in restimulated cells. These observations were supported by quantitative image analysis that showed a significant decrease in GrB colocalisation with Lamp (Figure 2e), confirming that TCR restimulation elicits LMP.

Taken together, these results show that although limited LMP and some GrB release occurs in activated T cells, death is prevented by Sb9. TCR complex restimulation markedly enhances LMP, increasing egress of GrB into the cytosol, which suggests it overwhelms Sb9 and kills the cell.

Cytosolic GrB is associated with but not essential for AICD of human NK cells. NK cell death following CD2 ligation is suggested, but not proven, to be GrB mediated, ${ }^{6}$ and it is unknown whether GrB release is a general feature of AICD in NK cells or whether it is receptor specific. To address these issues we examined IL-2-activated human NK cells. Analysis by immunoblotting showed that little GrB is expressed in freshly isolated NK cells until day 4 (Supplementary Figure 1c). Ligation of either CD2 or CD16 receptors resulted in LMP, as indicated by release (decreased fluorescence) of Lyosotracker Green (Figure 3a). Receptor ligation also induced rapid death (Figure $3 \mathrm{~b}$ ) and release of active GrB into the cytosol - as indicated by the detection of $\mathrm{Sb9} / \mathrm{GrB}$ complexes in extracts 
a
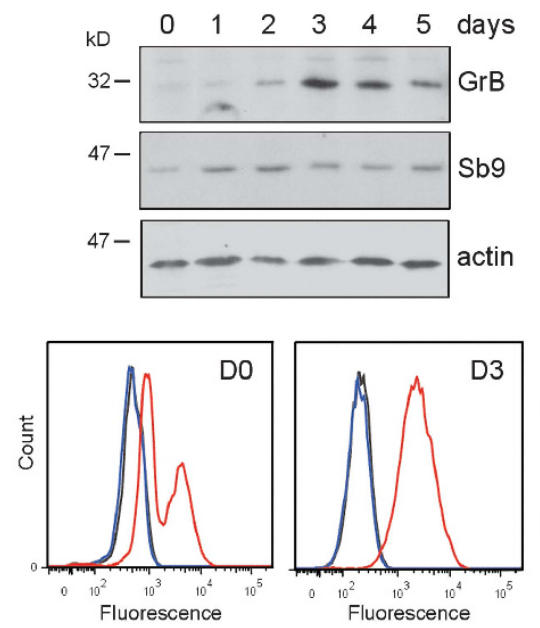

c
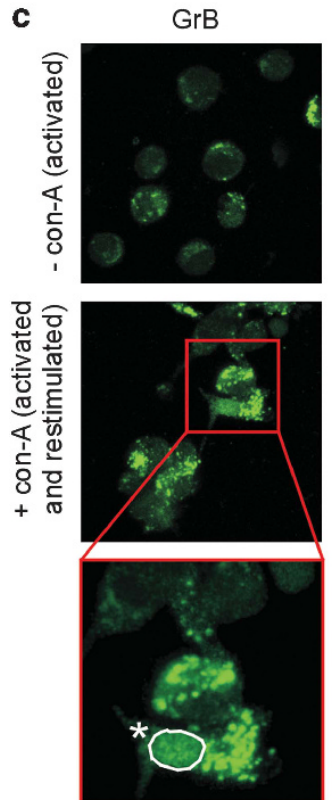

b

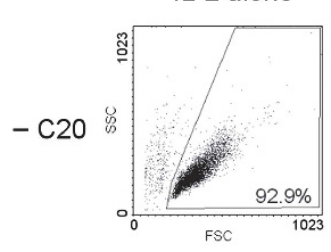

A568 alone

isotype/A568

GB11/A568

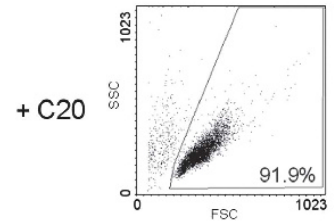

Lamp + GrB merge
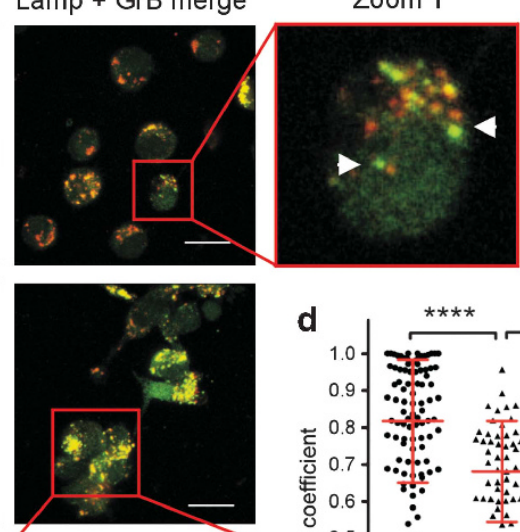

Zoom 3

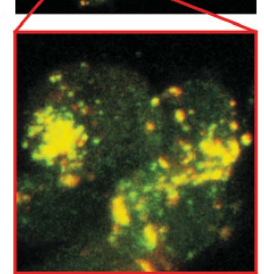

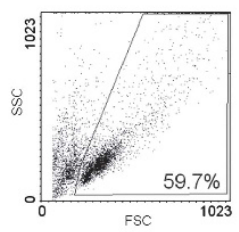

Con A / IL-2
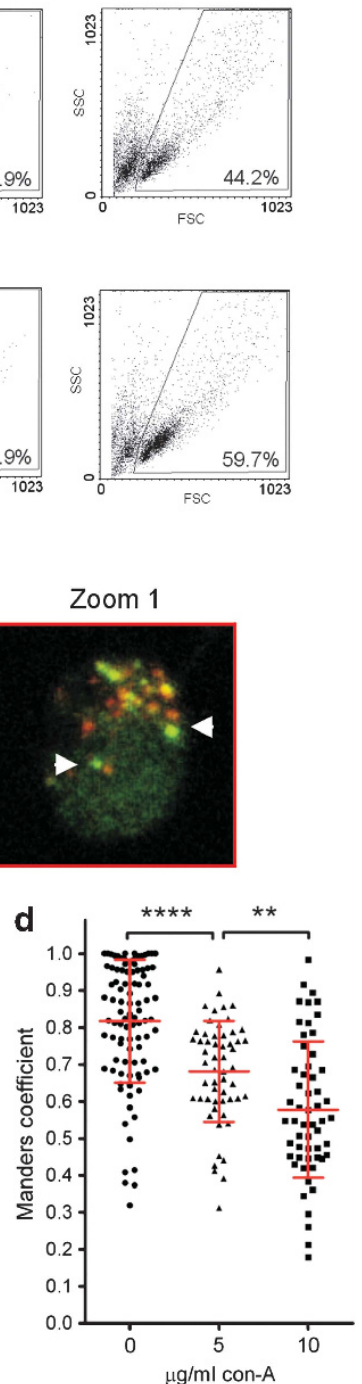

Figure 1 Restimulation induced cell death in human $\mathrm{CD}^{+}{ }^{+} \mathrm{T}$ cells involves $\mathrm{GrB}$. (a) CTLs were activated with $5 \mu \mathrm{g} / \mathrm{ml}$ con-A and IL-2. Cells were lysed in LSB and GrB, Sb9 and actin levels determined by sequential probing of an immunoblot. GrB expression on day 3 was also determined by FACS analysis. Cells were fixed with paraformaldehyde, permeabilised with $0.1 \%$ saponin in Hank's balanced salt solution (HBSS), then stained with either isotype control (MOPC31) or GB11 followed by antimouse Ig conjugated to Alexa Fluor 568. (b) Activated cells were 'rested' for 3 days in medium with IL-2 alone. Cells were pretreated, or not, with $100 \mu \mathrm{M} \mathrm{C20} \mathrm{for} 3 \mathrm{~h}$ then restimulated with $5 \mu \mathrm{g} / \mathrm{ml}$ con-A/IL-2. Survival was determined after $4 \mathrm{~h}$ by FACS analysis. PI exclusion confirmed that only the gated cells were viable (not shown). (c) Activated cells were 'rested' then restimulated for $4 \mathrm{~h}$ with con-A/L-2 in the presence of nocodazole. Lamp 1 was detected with a sheep polyclonal antibody, and GrB with GB11. Images were collected using constant instrument settings optimised for 'treated' samples. Some untreated cells showed minor LMP and GrB release ( - con-A, zoom 1, arrow heads). Zoom 2 indicates a treated cell with cytosolic and nuclear GrB ("nucleus is circled). Zoom 3 shows reduced coincidence of GrB and Lamp staining. Shown are deconvolved image stacks. Bar $=10 \mu \mathrm{m}$. (d) Colocalisation analysis was performed and the Manders' coefficient indicating the extent of GrB overlap with Lamp is shown graphically. Each point represents one cell ( $n=95$ for 0 con-A; $n=56$ for each 5 and $10 \mu \mathrm{g} / \mathrm{ml}$ con-A) and the bars are mean \pm S.D.

of cells processed to prevent post-lysis complex formation ${ }^{12}$ (Figure 3c). However, pretreatment with C20 failed to protect the cells from death (Figure 3d), even though it substantially reduced cytosolic GrB activity, as indicated by the marked reduction in Sb9/GrB complexes (Laemmli sample buffer (LSB) samples, Figure 3e; control experiments confirmed that most endogenous $\mathrm{GrB}$ was inactivated by $\mathrm{C} 20$, as indicated by loss of post-lysis complexes in C20-pretreated cell extracts (NP40 extracts, Figure 3e)). These data suggest that LMP and release of LRO contents is a general feature of
AICD in NK cells. However, although GrB is released into the cytosol, it is apparently not required for cell death.

GrB release from LROs follows, and is proportional to, LMP. Why is cytosolic GrB associated with death of CTL but not NK cells? Assuming in both cell types the LRO content released is proportional to the degree of LMP, the simplest explanation is that LRO protein complement is different, and that a second effector (and/or LRO) is present in NK cells but not in CTLs. Alternatively, differences in LRO structure or 
a

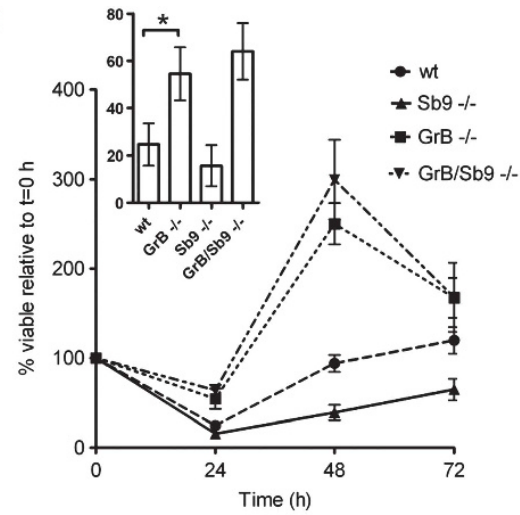

d
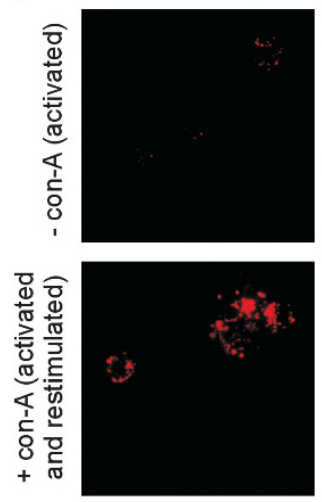
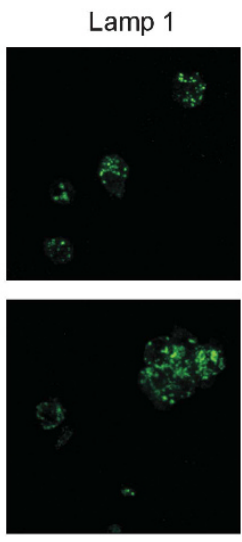

b

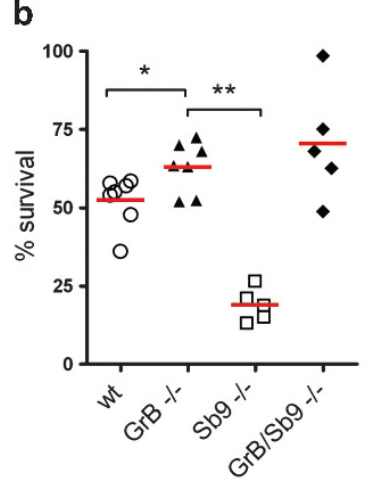

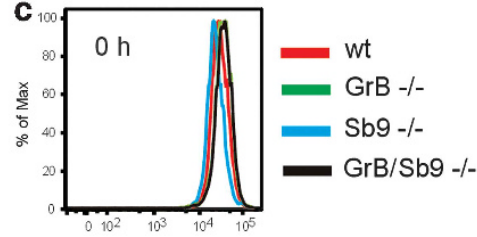

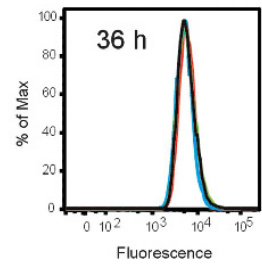

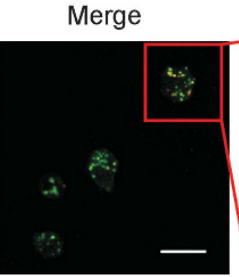

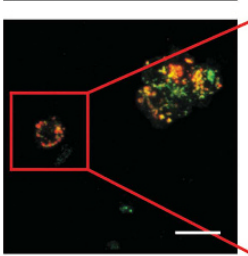

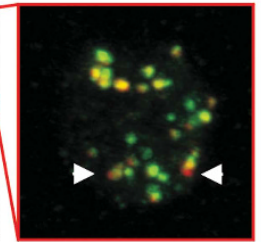

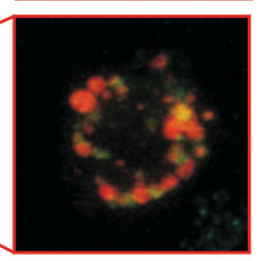

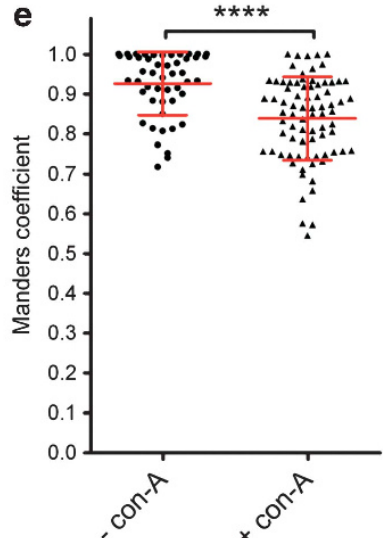

Figure 2 Restimulation of mouse T cells induces LMP and GrB-mediated death, and Sb9 enhances cell survival. (a-c) Splenocytes activated with anti-CD3/anti-CD28 and IL-2/IL-7 were cultured in fresh medium containing IL-2 alone for 24-48 h. (a) Splenocytes were restimulated with con-A for up to $72 \mathrm{~h}$. Viability was determined using AO/ ethidium bromide staining. Data shown are pooled from four to six independent experiments. Inset is a graph showing the \% survival at $24 \mathrm{~h}$. (b) Splenocytes were restimulated on immobilised anti-CD3 for $36 \mathrm{~h}$ and cell survival assessed by FACS analysis. Shown are pooled data from at least three independent experiments. Each point represents cells isolated from one mouse and the bar indicates the mean \% survival. (c) Celltracker orange dilution was used to measure cell division. Activated cells were loaded with the dye following the manufacturer's instructions, then restimulated with immobilised anti-CD3 for $36 \mathrm{~h}$. The mean fluorescence intensity before and after restimulation was measured by FACS analysis. (d) Splenocytes from Jinx mice (which inefficiently degranulate) were restimulated with con-A for $4.5 \mathrm{~h}$, then fixed for immunocytochemistry. GrB was detected with GB11 and Lamp 1 with 1D4B. All images were collected using the same instrument settings optimised for 'treated' samples. A cell in the untreated population has LROs undergoing LMP and GrB release (arrow heads). Shown are deconvolved image stacks. Bar $=10 \mu \mathrm{m}$. (e) Colocalisation analysis was performed as in Figure $1 \mathrm{~d}(n=50$ for con- $\mathrm{A}$ and 78 for + con- $\mathrm{A})$

signalling pathways may result in cell-specific outcomes following LMP, for example, the previously suggested selective release of GrB from CTL LROs. ${ }^{19}$ To address these issues we used well-characterised lysosomotropic compounds, sphingosine and Leu-Leu-methyl-ester (LLOMe), which induce LMP, release of lysosomal proteins and apoptosis in many cell types. ${ }^{26,27}$ As the use of these model inducers in CLs has not been reported, we first examined their effect on human NK-like cell lines. To monitor LMP, NK cells were loaded with acridine orange (AO). When exposed to blue light, AO fluoresces red at high concentration (lysosomes) and green at low concentrations (cytosol and nucleus), which can be measured by flow cytometry. Induction of LMP causes leakage of AO into the cytosol, increasing green fluorescence and decreasing red fluorescence.

As shown in Figure 4a, LLOMe caused translocation of AO in YT cells in a dose-dependent manner. LRO damage was also indicated by changes in organelle $\mathrm{pH}$ and was associated with progressive release of GrB (Figure 4b). Here we used live cell imaging to monitor LLOMe-induced LMP in YT cells expressing a lysosome-targeted $\mathrm{pH}$-sensitive reporter comprising GrB fused to enhanced green fluorescent protein (eGFP). ${ }^{28}$ This reporter, GrB-eGFP, is 'dark' at the low $\mathrm{pH}$ normally found in lysosomes, but becomes fluorescent as the $\mathrm{pH}$ approaches neutral. Before exposure to LLOMe, GFP was visible in very few cells expressing this reporter. However, within 5 min individual granules became visible (white arrows) and after $40 \mathrm{~min}$ most cells displayed numerous granules and/ or diffuse cytosolic GFP. Finally, indirect immunofluorescence (Figure 4c) shows marked enlargement of Lamp 2 vesicles within $20 \mathrm{~min}$, consistent with rapid lysosomal swelling. ${ }^{27} \mathrm{GrB}$ fluorescence was enhanced in vesicles of treated cells and was also apparent in the cytosol. Many cells showed mainly cytosolic GrB staining along with morphological changes indicative of apoptosis. Together, these data show that LLOMe induces generalised LMP and release of GrB in CLs.

Release of endogenous GrB over time was also followed via preformed SDS-stable GrB/Sb9 complexes in cell extracts (Figure 4d). This showed that the amount of GrB in the cytosol 
a

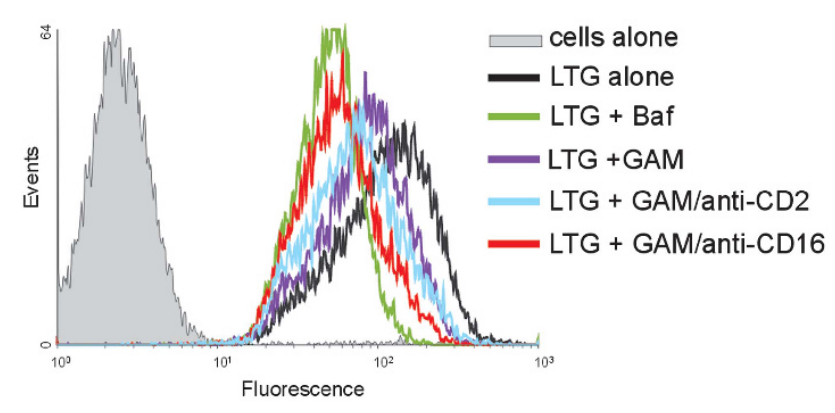

b
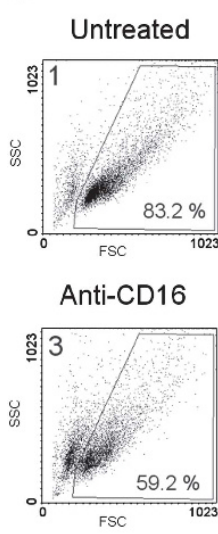

c

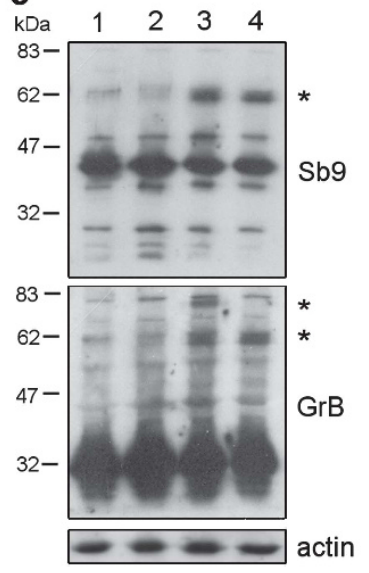

d
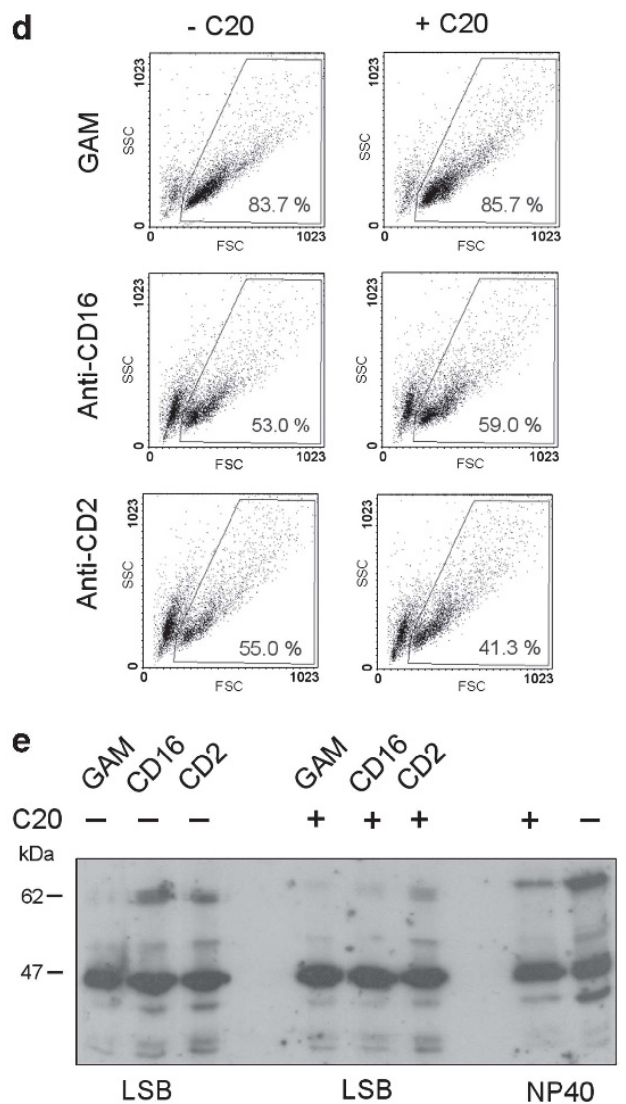

Figure 3 AICD follows receptor-mediated LMP and GrB release in human NK cells. (a) IL-2-activated NK cells were loaded with Lysotracker Green (LTG), then incubated with either anti-CD2 or anti-CD16 mAbs cross-linked using goat anti-mouse antibody (GAM), or GAM alone, or bafilomycin A1. (b and c) Activated cells were either untreated, exposed to anti-CD2 or anti-CD16 together with GAM antibody, or exposed to GAM antibody alone for $2 \mathrm{~h}$ at $37^{\circ} \mathrm{C}$. Cells from the same experiment were analysed by FACS analysis for cell survival (b) or lysed in LSB for immunoblotting (c). The numbered lanes correspond to the indicated FACS plots. *Sb9/GrB complexes. A single membrane was probed sequentially for Sb9 (R11), GrB (R041) and actin proteins. (d and e) The experiment described above was repeated, but NK cells were first incubated with and without $\mathrm{C20}$, then exposed to antibodies in the presence of $\mathrm{C20}$. Cells were analysed by FACS analysis for cell survival (d) or by immunoblotting for complexes formed before lysis (e; LSB). NK cells pretreated with C20 but not exposed to mAbs were lysed in NP40 to ascertain the efficiency of GrB inhibition by C20, as indicated by a reduction of Sb9/GrB complex formation post lysis (e; NP40). The immunoblot was probed with anti-Sb9 (R11)

increases with length of exposure to the LMP inducer. We also found that GrB release and cell death is proportional to LLOMe concentration - at higher LLOMe concentrations, more $\mathrm{GrB}$ is released and larger numbers of cells die (Figure $4 \mathrm{e}$, right panel). Sb9/GrB complexes formed prelysis increased with the concentration of LLOMe applied (Figure 4e, left panel), but importantly were evident at concentrations at which no cell death occurred $(20-50 \mu \mathrm{M})$. At concentrations higher than $50 \mu \mathrm{M}$, complex formation increased but cell survival decreased markedly, suggesting that beyond this point another cytotoxin comes into play (ample uncomplexed Sb9 was still present to interact with GrB and complex formation continued to increase). This is consistent with data presented in Figure 3. Similar results were obtained with sphingosine and a second NK-like cell line (Supplementary Figure 2).

Taken together, these results show that generalised LRO destabilisation and LMP can be induced in CL, resulting in proportional, progressive GrB release into the cytosol. If not controlled by $\mathrm{Sb9}$, this results in cell death.
GrB is a prime effector of LMP-mediated death in both CL subsets, but is dispensable in NK cells. Although LMP drives GrB release into the CL cytoplasm, it is not clear whether this ectopic GrB is necessary or sufficient to kill the cell. To address this issue, we compared the effect of LLOMe on primary activated human CTL or NK cells (Figure 5). CTL exposed to LLOMe underwent rapid apoptosis (as indicated by annexin $\mathrm{V}(\mathrm{AV})$ and propidium iodide (PI) staining), with maximal cell death after $\sim 2 \mathrm{~h}$ (Figure $5 \mathrm{a}$, left panel). Pretreatment with $\mathrm{C} 20$ conferred significant protection, resulting in a $50 \%$ decrease in apoptosis, confirming GrB as an important mediator of LMP-mediated death of T cells. By contrast, pretreatment with C20 did not affect overall survival of NK cells exposed to LLOMe, although it did significantly delay onset of apoptosis, indicating a role for GrB early in the process (Figure 5a, right panel).

To examine this further, we used time-lapse microscopy to determine the times after addition of LLOMe at which individual NK cells show the classic features of apoptosis: membrane blebbing, phosphatidyl serine externalisation 
a

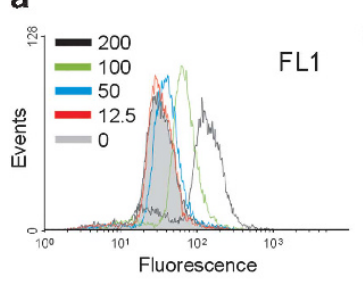

C
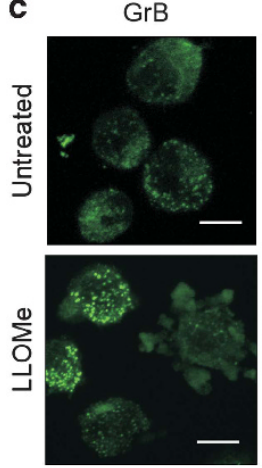

e

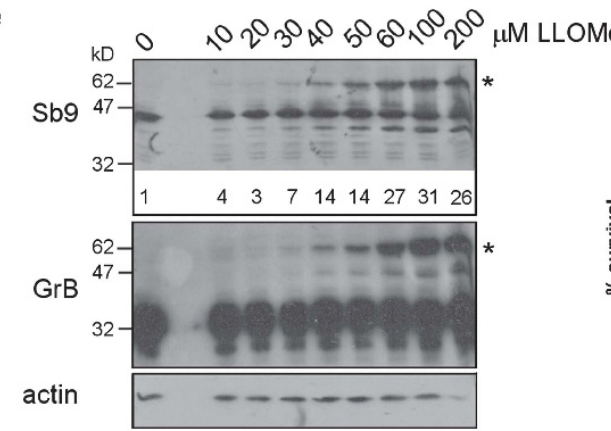

b
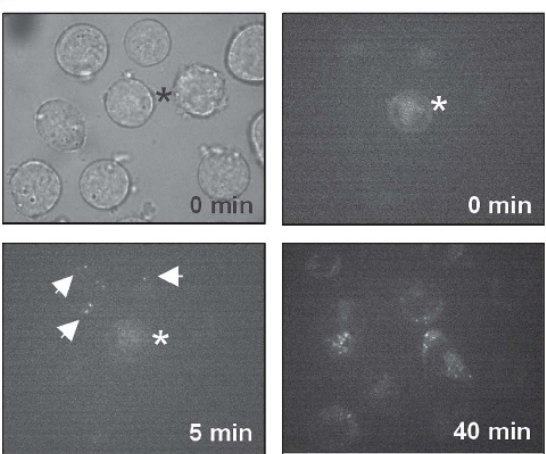

Lamp 2
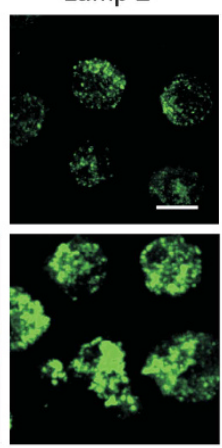

FL3

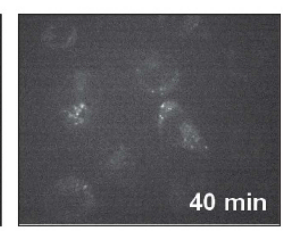

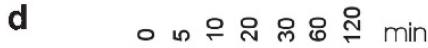

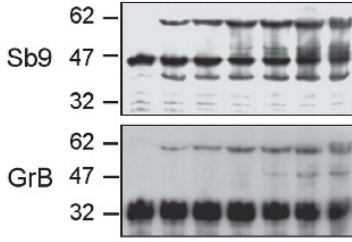

actin $47-\ldots$

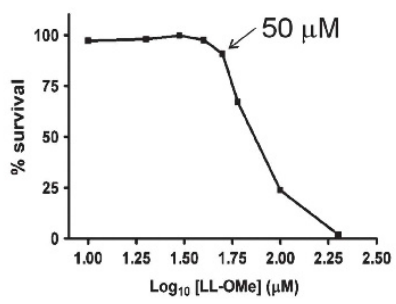

Figure 4 LMP, release of GrB and cell death increases with rising doses of lysosomal stressors. Human NK-like cells, YT, were treated with the lysosomal disruptor LLOMe and LRO damage monitored. (a) Cells were loaded with $\mathrm{AO}$ and exposed to the indicated concentrations $(\mu \mathrm{M})$ of LLOMe for 30 min. $\mathrm{AO}$ redistribution was determined by FACS analysis. Minor LMP and release of AO is indicated by increased FL1 but unaltered FL3 fluorescence; significant LMP/granule damage results in increased FL1 and decreased FL3 fluorescence. (b) YT cells expressing GrB-eGFP were exposed to $250 \mu \mathrm{M}$ LLOMe. GFP fluorescence was monitored over $2 \mathrm{~h}$. Shown are single optical sections and a bright-field image at $t=0 \mathrm{~min}$. ${ }^{*} \mathrm{~A}$ cell which is $\mathrm{GFP}^{+}$before addition of LLOMe. Arrows indicate individual LROs that have become fluorescent after 5 min. (c) Cells were exposed to $250 \mu \mathrm{M}$ LLOMe for $20 \mathrm{~min}$. Changes in GrB and Lamp 2 distribution were monitored by indirect immunofluorescence using GB11 or H4B4 antibodies. Shown are representative images. Bar $=10 \mu \mathrm{m}$. (d) Cells were exposed to $200 \mu \mathrm{M}$ LLOMe for the indicated times (min), lysed in LSB and extracts analysed by immunoblotting. (e) Individual aliquots of YT cells were exposed to increasing concentrations of LLOMe for $30 \mathrm{~min}$. Each aliquot was divided in two to assess cell survival (right panel) and the amount of preformed complex formation (left panel). The membrane was probed sequentially for GrB, Sb9 (R11) and actin proteins. ${ }^{*} \mathrm{Sb} 9 / \mathrm{GrB}$ complexes. The amount of preformed complex $\left(^{*}\right)$ detected by the Sb9 antibody was estimated by densitometric analysis using the image processing software Image $\mathrm{J}$. The boxed values below the Sb9 immunoblot indicate the intensity of bands relative to the same band in the untreated lane

(FITC-AV binding) and membrane disruption (PI uptake; Figure 5b). Although C20 pretreatment did not alter time to death, it did significantly increase the mean time to membrane blebbing and AV positivity, confirming that GrB contributes to early onset of apoptosis but is not essential for LMP-mediated death of NK cells. Control experiments showed that cells sensitive to LLOMe, but lacking GrB, are unaffected by C20 pretreatment, confirming GrB selectivity of C20. Furthermore, the mean time to membrane blebbing in the control cells was similar to the time noted for C20-treated NK cells, suggesting common lysosomal constituents contribute to cell death in the absence of GrB (Supplementary Figure 3).

Our data suggest that CTL and NK cells store different proteins in their LROs. GrB is the major cytotoxin released from T-cell LROs, whereas in NK cells it is released but not essential for LMP-mediated death. An obvious possibility is that other granzymes contribute to death in NK cells. Granzyme A (GrA) is in both CTL and NK cells, and granzyme $M(G r M)$ is mainly in NK cells. ${ }^{29}$ Because selective inhibitors do not exist, we investigated the contribution of GrA and GrM to LMP-mediated death using CLs taken from gene-targeted mice. (The contribution of the related granzyme GrK could not be determined as null mice are not available). As expected, we found markedly improved survival of T cells lacking GrB, and observed almost complete survival of cells lacking both GrA and GrB (Figure 6a), indicating that in T-cells GrB is the main factor and that GrB and GrA alone are responsible for LMP-mediated cell death. Given that GrB is the most cytotoxic 
a

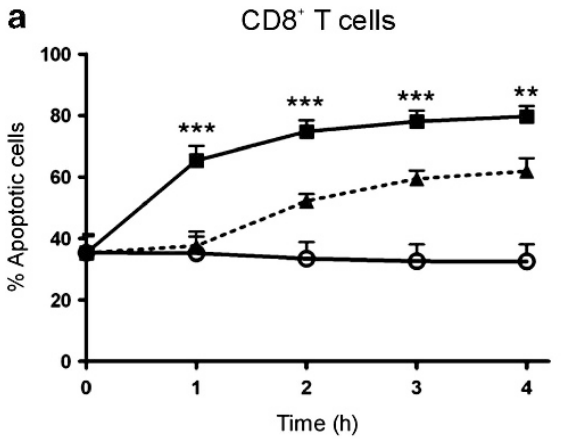

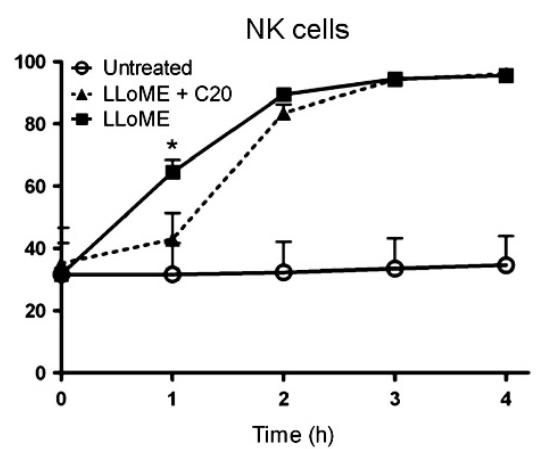

Bleb-, AV-, PI-

$\mathrm{Bleb}+, \mathrm{AV}-\mathrm{PI}-$

$B l e b+, A \bigvee+, P I-$

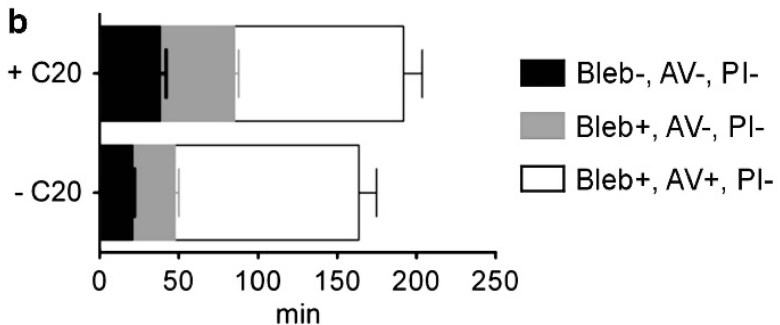

Figure 5 LLOMe-induced apoptosis is primarily GrB-mediated in human CTL but not in human NK cells. Activated CTLs (a) and NK cells (a and b) were pretreated, or not, with C20 then exposed to $250 \mu \mathrm{M} \mathrm{LLOMe,} \mathrm{AV} \mathrm{and} \mathrm{PI.} \mathrm{(a)} \mathrm{\%} \mathrm{Apoptosis} \mathrm{was} \mathrm{determined} \mathrm{at} \mathrm{hourly} \mathrm{intervals} \mathrm{by} \mathrm{FACS} \mathrm{analysis.} \mathrm{Data} \mathrm{are} \mathrm{pooled} \mathrm{from} \mathrm{at} \mathrm{least} \mathrm{eight} \mathrm{independent}$ experiments for CTLs and five independent experiments for NK cells. LLOMe-treated cells showed significantly less death if pretreated with $\mathrm{C} 20\left({ }^{\star} P<0.05\right.$; ${ }^{* *} P<0.01$; ${ }_{* \star *} P<0.001$ ). (b) NK cell death was monitored at $3 \mathrm{~min}$ intervals for $6 \mathrm{~h}$ by time-lapse microscopy. The duration from addition of LLOMe to appearance of membrane blebbing, AV binding and PI uptake was recorded for 30-50 individual cells (data are pooled from two separate experiments). Black bars indicate time during which cells showed normal morphology, grey bars indicate time when cells showed membrane blebbing but were not AV or PI positive, and white bars show time when cells showed both membrane blebbing and AV staining but were not PI positive. Cells were positive for PI staining at times later than that indicated by the white bars

LRO constituent and that Sb9 is a specific inhibitor, we predicted that the absence of $\mathrm{Sb} 9$ should enhance sensitivity to LMP. Indeed, we found that cells lacking Sb9 were sensitive to lower concentrations of LLOMe and that overall survival was much poorer than wt $T$ cells (Figure $6 b$ ). Importantly, deletion of both $\mathrm{GrB}$ and $\mathrm{Sb9}$ rescued cells, confirming that Sb9 controls GrB activity in the CTL cytosol. By contrast, simultaneous deletion of $\mathrm{GrA}$ and $\mathrm{GrB}$ failed to protect splenic NK cells from LMP-mediated death (Figure $6 \mathrm{c}$ ), consistent with the observation that GrB is not essential for LMPmediated death in human NK cells, and ruling out a major role for GrA. However, as noted in the human system, the absence of GrB delayed the onset of death and substantially increased the proportion of cells dying by necrosis (Figure 6d). Additional deletion of GrM also failed to rescue LLOMe-treated cells (Figures $6 \mathrm{c}$ and d) showing that mouse GrM is not the second cytotoxin in NK cells. Similar results were observed when NK cells from wt or GrA/B/M-deficient mice were exposed to sphingosine (data not shown). We conclude that GrB can initiate apoptosis in NK cells but death can be augmented by a second factor.

The GrB-Sb9 nexus controls the response of working NK cells to low-level LMP. Two observations suggest that Sb9 is important in NK cells under conditions of limited LMP. Preformed GrB/Sb9 complexes were detected in purified, untreated human NK cells (Figures $3 \mathrm{c}$ and e) and Sb9 protected YT cells treated with concentrations of LLOMe which induced minor GrB release (Figure 4e). Together, these data suggest that the additional cytotoxic constituent(s) released from NK granules is either less potent than GrB or is present at lower levels. Significant LMP in the absence of GrB results in delayed onset of apoptosis, but ultimately death is unaffected.

Cross-linking of NK cell receptors or exposure to high concentrations of LLOMe in model systems probably causes more extensive LMP than that occuring during proliferation or AICD in physiological settings such as target cell engagement. If so, the importance of the Sb9-GrB nexus in AICD may be masked in culture by the supraphysiological release of other lysosomal constituents.

CLs die during encounters with targets. ${ }^{30-34}$ Hence, we further examined the relationship between LMP, GrB release and interaction with $\mathrm{Sb9}$ in NK cells engaged in target cell killing. Using time-lapse microscopy, we detected death of human NK cells following target cell engagement (Figure 7a). Indirect immunofluorescence (Figures $7 \mathrm{~b}$ and c) showed that in most NK cells GrB colocalised with Lamp 1. As reported previously, ${ }^{16}$ Sb9 was both cytosolic and nuclear, and it colocalised with essentially all GrB-positive Lamp 1-positive structures, indicating that it concentrates around LROs where it would be positioned to trap leaking GrB (Figure $7 \mathrm{~b}$ ). ${ }^{15}$ In $\sim 30 \%$ of cells, cytosolic GrB was evident. In most cases, only a limited number of LROs appeared to be compromised (Figure 7c, upper panel); however, we observed some cells in which most LROs had released GrB (Figure 7c, lower panel). Finally, galectin 8 staining was used to identify LROs that had been compromised. The galectins are $\beta$-galactoside-binding proteins found both extracellularly and in the cytosol, which is normally devoid of complex carbohydrates. When the membrane of an endosome or lysosome is damaged, the galectins transiently bind the exposed charbohydrate 
a

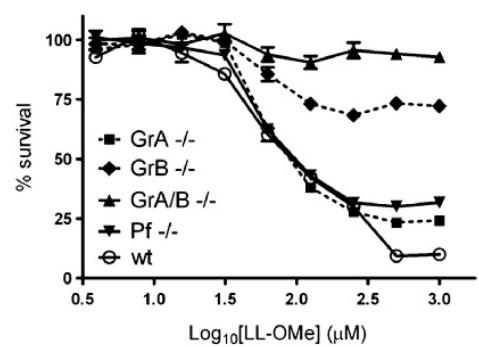

C

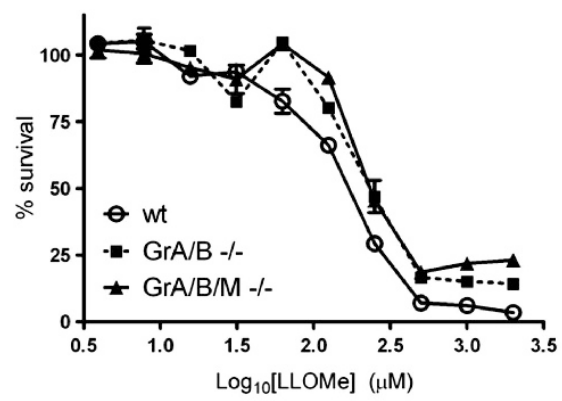

b

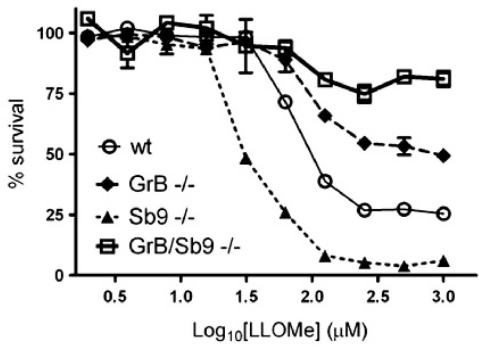

d

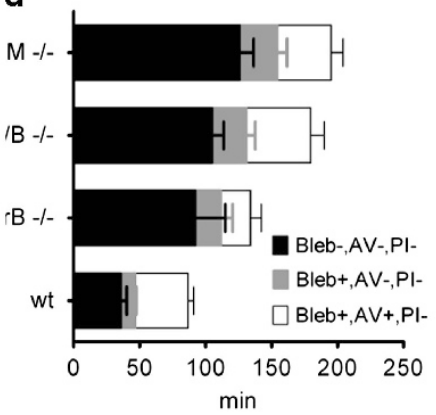

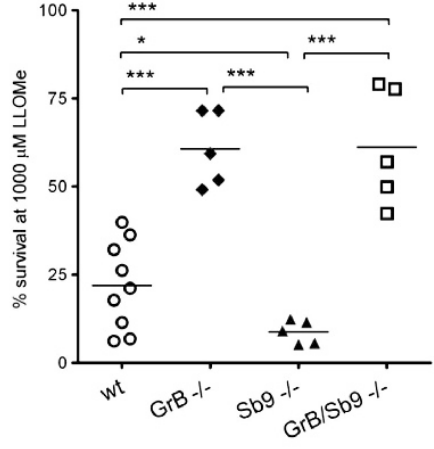

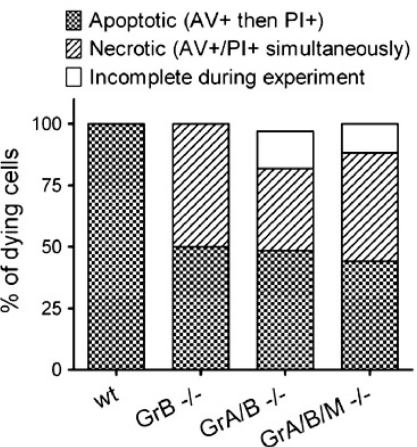

Figure $6 \mathrm{GrB}$ is the key initiator of death in response to LRO damage in activated mouse splenic T cells but not in NK cells. (a and $\mathbf{b})$ Con-A activated splenocytes were exposed to two-fold serial dilutions of LLOMe and survival assessed $18 \mathrm{~h}$ later by MTT assay. Shown are survival curves from representative experiments. Data are mean and S.D. of triplicates. (b, left panel) Survival curves were generated for each of the indicated genotypes in at least 5 separate experiments (one representative data set is shown). The \% survival of splenocytes in $1 \mathrm{mM}$ LLOMe was determined from the curves and pooled data presented as a vertical scatter plot (b, right panel) where each point represents cells isolated from one mouse and the bar indicates the mean \% survival. (c) Activated splenic NK cells were exposed to two-fold serial dilutions of LLOMe and survival assessed $18 \mathrm{~h}$ later using CellTiter Glo. Survival curves were generated for each genotype in at least three separate experiments: a representative data set is shown. Data are mean and S.D. of triplicates. (d) NK cells were cultured with PI, FITC-AV and $250 \mu \mathrm{M} \mathrm{LLOMe,} \mathrm{and} \mathrm{monitored} \mathrm{by} \mathrm{time-lapse} \mathrm{microscopy.} \mathrm{Images} \mathrm{were} \mathrm{captured} \mathrm{at} 2$ min intervals over $5 \mathrm{~h}$. (d, left panel) The time at which individual cells began to show membrane blebbing, became $\mathrm{AV}^{+}$or became $\mathrm{PI}^{+}$was determined and the means $\pm \mathrm{S}$.E.M. shown graphically. (d, right panel) The type of death (necrotic or apoptotic) and proportion of cells, which did not die during the experiment is also shown

normally found within these vesicles and marks the vesicles for removal by autophagy. ${ }^{35,36}$ We found that galectin 8 colocalised with GrB-positive vesicles in NK cells on targets, indicating that these LROs have damaged membranes (Figure 7d). Thus, it appears that LMP and release of GrB from LROs occurs as NK cells are working and Sb9 is positioned to oppose cytosolic GrB.

To translate these findings into an in vivo setting, we infected mice with Ectromelia virus-Moscow strain. Recovery from this natural mouse pathogen critically depends on the granule pathway of CLs. ${ }^{37}$ After 2 days, the focus of infection is the draining lymph nodes and the major effectors are nonproliferating NK cells that recognise and destroy infected cells. ${ }^{37,38}$ Hypothesising that ectopic GrB contributes to death of effectors during engagement with virally infected cells, we predicted and found that Sb9-deficient NK cells in infected lymph nodes show significantly increased commitment to death via AV staining, compared with wt NK cells (Figure 7e). This increase was not evident in NK cells from mice lacking both $\mathrm{GrB}$ and Sb9, proving that GrB is a significant contributor to NK cell death in this setting. As no decrease in NK cell death was observed in GrB-deficient mice, we suggest that GrB can be reinforced and/or replaced by a second effector, as indicated by our in vitro experiments (Figure 6).

\section{Discussion}

Populations of CLs expand in response to an immune challenge and contract when the challenge has been successfully met. The molecular mechanisms driving contraction of effector cell populations are complex and not fully understood; however, in the case of T cells, old or superfluous cells die by apoptosis in response to either extrinsic signals via death ligands such as FasL or TNF, or in response to intrinsic signals via the BH3-only protein, Bim, arising from cytokine or growth factor depletion. ${ }^{1,2}$ Operation of these two contraction mechanisms is not mutually exclusive and probably depends on the type, class and differentiation state of the cell, and on its environment.

GrB has been implicated in AICD, but when and how it accesses the cytosol is unclear. Here we have shown that receptor restimulation of activated CLs results in LMP. This is clearly illustrated by the following: (1) almost total loss of Lysotracker Green fluorescence in NK cells treated with antiCD16 antibodies; (2) GrB outside LROs in restimulated T cells; (3) preformed Sb9/GrB complexes in the cytosol; and (4) binding of galectin 8 to LROs with membrane damage. We also detect LMP in rapidly proliferating (mitogen stimulated) $\mathrm{T}$ cells and activated (but not restimulated) lymphocytes, suggesting that a basal level of LMP is normal. 
a

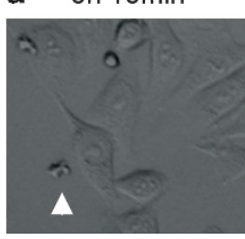

Oh $45 \mathrm{~min}$

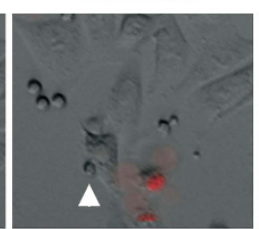

1h Omin

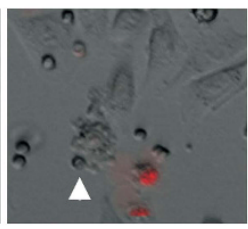

$1 \mathrm{~h} 30 \mathrm{~min}$

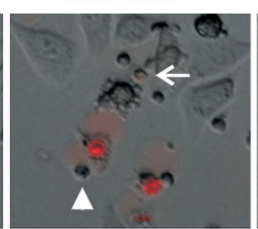

$2 \mathrm{~h} 30 \mathrm{~min}$

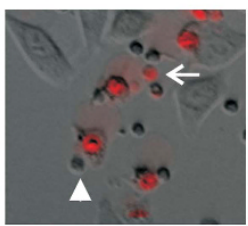

$3 \mathrm{~h} 25 \mathrm{~min}$

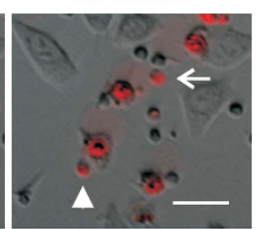

b $\quad \mathrm{Sb} 9$

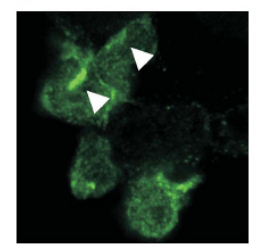

Lamp 1
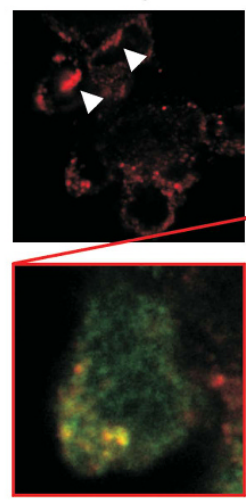

Sb9/Lamp 1 merge Lamp 1/GrB merge
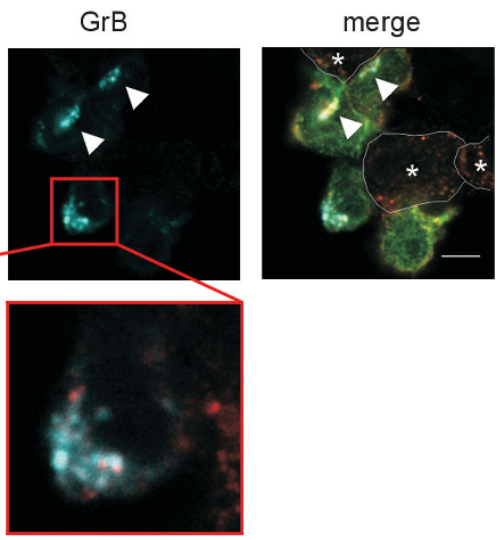

d

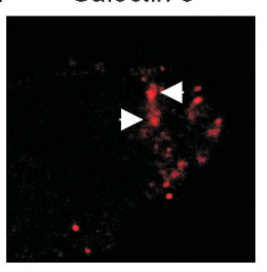

e
GrB

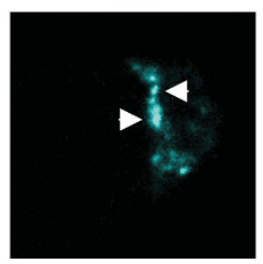

z stack
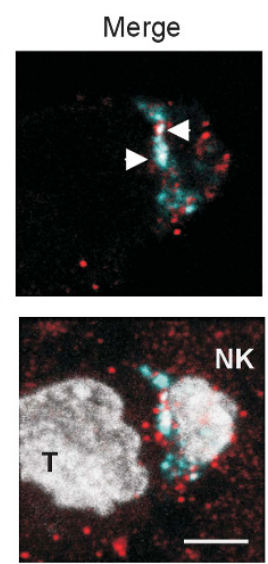

c Limited LMP
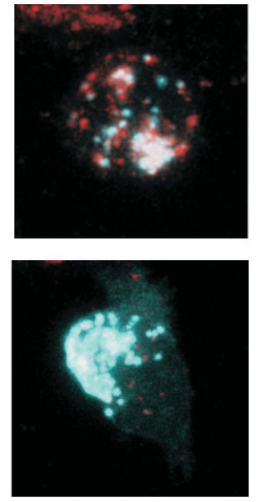

Generalised LMP

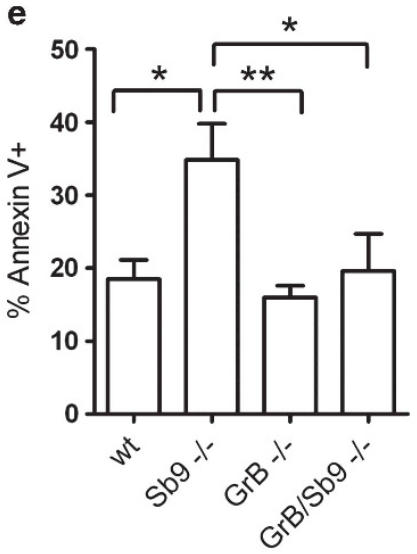

Figure 7 Sb9 protects NK cells from low-level LMP and release of GrB. (a) Time-lapse microscopy of purified human NK cells on HeLa target cells. Two NK cells (arrow and arrow head) become $\mathrm{PI}^{+}$following target cell engagement. Bar $=20 \mu \mathrm{m}$. (b) MM-170 target cells were co-cultured with purified, activated human NK cells for $1 \mathrm{~h}$, then

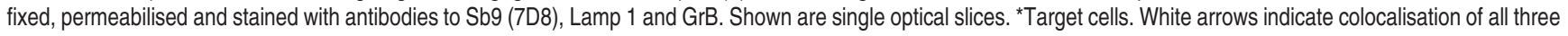
proteins. Bar $=5 \mu \mathrm{m}$. The boxed cell is enlarged and a merge of Sb9 and Lamp 1 (left panel), and Lamp 1 and GrB (right panel) are shown. (c) Examples from the above experiment of cells showing limited and generalised LMP. Shown are three-dimensional reconstructions of merged Lamp 1 (red) and GrB (cyan) staining. (d) MM170 cells were cultured with NK cells for $1 \mathrm{~h}$ then fixed and permeabilised with SDS. Cells were stained with DAPI and antibodies to galectin 8 and GrB. The lower panel is a merged $z$-stack and shows that the NK cell is attached to a target cell (T). Galectin 8 and GrB staining in a single optical slice are shown; the arrows indicate areas of colocalisation. $B a r=5 \mu \mathrm{m}$. (e) Mice were infected with Ectromelia virus-Moscow strain and poplitial lymph nodes taken 2 days post infection. Cells were stained with Aqau ALIVE/DEAD stain, followed by antibodies to NK1.1 and CD3. Finally, cells were stained with AV, fixed and analysed by FACS analysis. The $\% \mathrm{AV}^{+} /$alive NK1.1 $1^{+} / \mathrm{CD} 3^{-}$cells is shown. Data are means and S.E.M. of pooled results from four independent experiments with a total of at least eight mice per genotype. Differences were considered statistically significant if the $P$ value was 0.05 or less $\left({ }^{*} P<0.05 ;{ }^{*} P<0.01\right)$

It is well accepted that a wide variety of stressors can cause LMP and translocation of lysosomal hydrolases into the cytosol, leading to cell death. ${ }^{22,23}$ Lysosomal protease inhibitors evident in the cytosol of many cells supports the notion that low-level LMP occurs constitutively, but goes undetected until the normal balance between protease and inhibitor is disturbed and pathologies result. Clearly then, the outcome of LMP depends on a number of variables - the degree of LMP, the type and level of proteases in the LRO, and the type and relative level of inhibitors in the cytosol. Each of these factors varies with cell type and the signals received from the environment. We find that LMP in human and mouse T cells, whether induced by LLOMe or restimulation, results in rapid killing of a proportion of the population by GrB unless negated by $\mathrm{Sb9}$ (or C20). This is also true for NK cells engaged with targets. These data show that in the case of mature CLs, the key protease inhibitor pair is GrB and Sb9. When LMP is low, Sb9 controls released GrB, but as LMP increases so does the level of GrB too until it overwhelms Sb9 and death ensues. Therefore, the survival of any $\mathrm{CL}$ 
undergoing LMP depends on the balance between the amount of GrB released and the level of active Sb9 in the cytosol.

Given that CLs kill multiple target cells sequentially, ${ }^{39,40}$ and each hit requires receptor engagement, the probability that a particular CL will succumb to LMP-induced death increases with age and the number of target cells it encounters. We therefore propose that activating receptor-driven LMP coupled to GrB-mediated death sets a natural limit on CL lifespan independently - but not exclusive of - growth factor availability or conventional death receptor signalling. This provides another avenue to effector cell population contraction and an additional layer of protection from immune pathology. In closing, we note that the apparent role of GrB in T-helper cell, ${ }^{18}$ Treg $^{41}$ and B-cell homeostasis ${ }^{42}$ may also be explained by its receptor-driven LMP-mediated release, and that virusinduced LMP and GrB-mediated suicide of infected CTL or NK cells may limit the spread of certain viruses. ${ }^{43}$

\section{Materials and Methods}

Cell lines and primary CLs. HeLa and MM-170 (human malignant melanoma) cells were used as NK cell targets. HeLa cells were cultured in DMEM with $10 \%$ fetal calf serum (FCS), $2 \mathrm{mM}$ glutamine, $50 \mathrm{U} / \mathrm{ml}$ penicillin and $50 \mu \mathrm{g} / \mathrm{ml}$ streptomycin. MM-170 cells were grown in RPMI-10 (RPMI 1640 with $10 \%$ heatinactivated FCS, glutamine, antibiotics as above and $90 \mu \mathrm{M} \beta$-mercaptoethanol). NK92 and YT cells are human NK-like cell lines. NK92 cells were maintained in Iscove's modified DMEM supplemented with $10 \%$ heat-inactivated FCS, antibiotics and $\beta$-mercaptoethanol. YT, Jurkat and THP-1 cells were grown in RPMI-10. Generation and characterisation of $Y T$ cells expressing GrB fused to eGFP has been reported. ${ }^{28}$

Human CLs were isolated from healthy informed volunteers. Peripheral blood mononuclear cells were purified by centrifugation through Ficoll-Paque Plus (GE Healthcare, Rydalmere, NSW, Australia). NK cells were isolated using magnetic beads coupled to CD56 (Miltenyi Biotec, North Ryde, NSW, Australia) and activated by culture in RPMI-CL (RPMI-10 medium with $0.1 \mathrm{mM}$ MEM non-essential amino acids and $1 \mathrm{mM}$ sodium pyruvate) and $100 \mathrm{U} / \mathrm{ml} \mathrm{IL}-2$ for 4 days. Activated NK cells were $>85 \% \mathrm{CD}^{+}{ }^{+}$as determined by fluorescence-activated cell sorting (FACS) analysis. CTLs were isolated on the basis of CD8 expression from the NK celldepleted mononuclear cells and were activated by culture in RPMI-CL containing $5 \mu \mathrm{g} / \mathrm{ml}$ con-A (Sigma-Aldrich, Sydney, NSW, Australia) and $100 \mathrm{U} / \mathrm{ml} \mathrm{IL-2} \mathrm{for} 3$ days. Purified CTLs were $74.14 \pm 8.01 \% \mathrm{CD}^{+}$.

Jinx mice (C57BL/6-Unc13d $\left.d^{\operatorname{lin} x} / \mathrm{Mmcd}\right)^{44}$ were obtained from the Mutant Mouse Regional Resource Center. CLs from these mice are unable to degranulate due to mutation of the UNC13D protein, which is required for the fusion of LRO with the plasma membrane. Mice deficient in $\mathrm{GrA}, \mathrm{GrB}, \mathrm{GrA} / \mathrm{B}, \mathrm{GrA} / \mathrm{B} / \mathrm{M}$ and $\mathrm{Pf}$ were obtained from the Peter MacCallum Cancer Centre, Melbourne, VIC, Australia. We have independently generated Sb9 and Sb9/GrB-deficient mice. The phenotypes are the same as previously described Sb9-null mice. ${ }^{17}$ Splenocytes were cultured at $5 \times 10^{6} /$ $\mathrm{ml}$ in RPMI-CL and polyclonaly activated by addition of $10 \mu \mathrm{g} / \mathrm{ml}$ con-A for 2 days or $0.1 \mu \mathrm{g} / \mathrm{ml}$ anti-CD3 and anti-CD28, $100 \mathrm{U} / \mathrm{ml} \mathrm{IL-2}$ and $2 \mathrm{ng} / \mathrm{ml} \mathrm{IL-7} \mathrm{for} 3$ days. Before restimulation, $\sim 80 \%$ of the population were $T$ cells, irrespective of the mouse line used $\left(24.2 \pm 5.5 \%\right.$ of the cells were $\mathrm{CD}^{+}, 48 \pm 4 \% \mathrm{CD}^{+}$, and $21 \pm 6 \%$ $\mathrm{CD}^{-} / \mathrm{CD}^{-}$) and $>90 \%$ were $\mathrm{GrB}$ positive. Mouse NK cells were isolated from the spleen using a negative selection kit according to the manufacturer's instructions (Mouse NK Isolation Kit, Miltenyi Biotec). Cells were cultured at a density of $7 \times 10^{5}$ cells/ml in RPMI-CL supplemented with $10 \mathrm{mM}$ Hepes and $1000 \mathrm{U} / \mathrm{ml} \mathrm{IL}-2$ for 6 days. FACS analysis of activated cells indicated that they were least $90 \% \mathrm{NK} 1.1^{+}$. For some experiments, dead cells were removed post activation by centrifugation over Ficoll-Paque Plus (GE Healthcare). Procedures involving animals followed National Health and Medical Research Council ethical guidelines, and was approved by Monash University Animal Ethics Committees.

Viral infection. Mice were injected subcutaneously (both lower hind limbs) with $6 \times 10^{3}$ pfu of Ectromelia virus-Moscow strain diluted in phosphate buffered saline (PBS; gift from M Regner and A Mullbacher, Australian National University, Canberra, Australia). Single-cell suspensions were prepared from popliteal lymph nodes 2 days post infection.
Antibodies and stains. Aqau ALIVE/DEAD stain (Invitrogen, Mulgrave, VIC, Australia); anti-CD2 (clone T11.3, IgG3, provided by E Reinhertz, Dana-Farber Cancer Institute, Boston, MA, USA); anti-CD16 (clone 3G8, Beckman Coulter, Sydney, NSW, Australia); goat anti-mouse Ig (GAM, Sigma-Aldrich); anti-mouse CD28 (clone 37.51, BioLegend, San Diego, CA, USA); anti-mouse CD3 (1452C11) and anti-mouse NK1.1 (PK136) (BD Biosciences, North Ryde, NSW, Australia); rabbit polyclonal antibodies to human (R11 and R15 (refs 15,45)) and mouse Sb9 (Hycult Biotech, Uden, The Netherlands ${ }^{46}$ ); anti-human Sb9 (clone 7D8 (ref. 47)); anti-human GrB for immunocytochemistry (clone GB11 (IgG1א), provided by $C$ Froelich, Northwestern University, Chicago, IL, USA) and GB11 directly conjugated to Alexa Fluor 647 (BD Biosciences); anti-human Pf (clone PB2 (ref. 48)) and anti-human GrB for immunoblotting (clone 2C5 (ref. 49)) were from J Trapani, Peter MacCallum Cancer Centre, Melbourne, VIC, Australia; antimouse GrB for immunoblotting (clone 16G6) and Annexin V (eBioscience, San Diego, CA, USA); rabbit polyclonal antibody (R041) raised to recombinant human $\mathrm{GrB}$ using standard methods; MOPC-31C mouse $\lg \mathrm{G} 1 \kappa$ isotype control (BD Biosciences); anti-actin (Santa Cruz Biotechnology, Santa Cruz, CA, USA); antihuman GrM (clone 4H10 (ref. 50)); anti-mouse Lamp 1 (clone 1D4B) and antihuman Lamp 2 (clone H4B4) (Developmental Studies Hybridoma Bank, lowa City, IA, USA)); sheep anti-human Lamp 1 (from J Hopwood, Women's and Children's Hospital, Adelaide, South Australia); species-specific HRP-conjugated secondary antibodies (Rockland Immunochemicals, Gilbertsville, PA, USA); anti-galectin 8 (Santa Cruz Biotechnology); Alexa Fluor-conjugated secondary antibodies (Molecular Probes, Eugene, OR, USA).

Activation-induced cell death. Activated human or mouse CTLs were washed and cultured for $24-96 \mathrm{~h}$ in RPMI-CL with $100 \mathrm{U} / \mathrm{ml}$ rlL-2 alone to 'rest' before restimulation with $5 \mu \mathrm{g} / \mathrm{ml}$ con-A. Activated human NK cells were washed in Hank's balanced salt solution, then resuspended in the same buffer with monoclonal antibodies to CD2 (1:200 of ascites) or CD16 (10 $\mu \mathrm{g} / \mathrm{ml} 3 \mathrm{G} 8)$ with or without the addition of cross-linking GAM $(10 \mu \mathrm{g} / \mathrm{ml})$ polyclonal antibody. After incubation at $37^{\circ} \mathrm{C}$ for 2 (NK cells) or $4 \mathrm{~h}$ (CTL), cell viability was assessed by FACS analysis to determine cell shrinkage (changes in FSC/SSC properties) and uptake of the vital dye PI. Alternatively, viability was determined microscopically using the vital stain $\mathrm{AO} /$ ethidium bromide. Activated splenocytes were also restimulated by plate-bound antiCD3 $(1 \mu \mathrm{g} / \mathrm{ml} 145-2 \mathrm{C} 11)$. Cells were collected at either 0 or $36 \mathrm{~h}$ after restimulation, washed and resuspended in PBS supplemented with $0.5 \%$ heat-inactivated FCS, $2 \mathrm{mM}$ EDTA, $1 \mu \mathrm{g} / \mathrm{ml}$ 4',6-diamidino-2-phenylindole (DAPI) and 20000 sphero beads (BD Biosciences). Populations were analysed on an LSRIl flow cytometer (BD Biosciences) and the number of viable or dead cells determined based on the number of beads counted. IL-2 $(50-100 \mathrm{U} / \mathrm{ml})$ was added to all experiments to minimise death due to cytokine withdrawal.

LRO integrity assay. Assessment of lysosomal membrane integrity in YT and NK92 cells was carried out essentially as described. ${ }^{27}$ Cells were cultured in medium containing $5 \mu \mathrm{g} / \mathrm{ml}$ AO (MP Biomedicals, Seven Hills, NSW, Australia) for $15 \mathrm{~min}$ at $37^{\circ} \mathrm{C}$, washed in RPMI-10, then incubated with various concentrations of LLOMe or sphingosine (Sigma-Aldrich) as indicated for 30 and $60 \mathrm{~min}$, respectively. After washing, changes in $\mathrm{AO}$ distribution were determined by FACS analysis using FL1 to monitor cytosolic $\mathrm{AO}$ and FL3 to measure LRO-associated AO. Alternatively, purified NK cells were cultured in medium containing $1 \mu \mathrm{M}$ Lysotracker Green (Molecular Probes) for $30 \mathrm{~min}$ after which they were treated with $100 \mathrm{nM}$ bafilomycin $\mathrm{A} 1$ (Sigma-Aldrich) or antibodies to CD2 and CD16 together with GAM for $40 \mathrm{~min}$ at $37^{\circ} \mathrm{C}$. After washing, cells were resuspended in PBS and analysed by FACS analysis.

Cell extracts and immunoblotting. Serpin/serine protease complexes are SDS stable and can be visualised by immunoblotting following separation by SDS/PAGE. Cell extracts for the analysis of complexes formed within the cell were prepared as described previously. ${ }^{12}$ Briefly, cell pellets were lysed in 1 volume of LSB. Under these conditions, LSB traps the SDS-stable complexes and prevents further complex formation post lysis. For analysis of GrB activity, complexes were allowed to form post lysis. Cells were lysed in half the volume of NP-40 lysis buffer $(50 \mathrm{mM}$ Tris HCL, pH 8.0, $10 \mathrm{mM}$ EDTA $1 \%(\mathrm{v} / \mathrm{v})$ Nonidet P40), then incubated at $37^{\circ} \mathrm{C}$ for $10 \mathrm{~min}$ (to allow complex formation), after which half the volume of $2 \times$ LSB was added. Viscosity was reduced by brief sonication. Cell extracts for the analysis of protein expression were prepared in LSB. Extracts from a defined number of cells were resolved by SDS/PAGE and transferred to nitrocellulose for immunoblotting. Target proteins were visualised by enhanced chemiluminescence. 
Survival curves. Cells in the appropriate medium were exposed to serial twofold dilutions of LLOMe for $30 \mathrm{~min}$, washed and resuspended in medium, and between $0.5 \times 10^{5}$ and $4 \times 10^{5}$ cells/well (depending on cell type) were plated in 96-well trays in triplicate for each treatment. Cell survival was assessed after $16 \mathrm{~h}$, generally by standard MTT assay. Where cell numbers were very low, cell survival was assessed using the CellTiter Glo Luminescent Cell Viability Assay (Promega, Alexandria, NSW, Australia) following the manufacturer's instructions. Mean and S.D. was calculated for each triplicate and data fitted to a sigmoidal dose-response curve using GraphPad Prism version 5.0 (GraphPad Software, La Jolla, CA, USA).

\section{Indirect immunofluorescence, microscopy and image processing.} Preliminary experiments showed that cells fixed at $37^{\circ} \mathrm{C}$ (rather than the usual room temperature) showed the best correlation of GrB and Lamp staining, and hence optimal preservation of granule integrity, in both YT cells and primary CLs (Supplementary Figure 4). Non-adherent cells were washed and resuspended in PBS, then incubated on glass slides pretreated with Cell-Tak (BD Biosciences) for $20 \mathrm{~min}$ at $37^{\circ} \mathrm{C}$. Where cells were subsequently exposed to further treatments, PBS was replaced with complete medium. Cells were fixed in $4 \%(w / v)$ paraformaldehyde in PBS for 20 min at $37^{\circ} \mathrm{C}$, quenched with $20 \mathrm{mM}$ ammonium chloride and permeabilised with $0.5 \%$ (v/v) Triton X-100 in PBS or $1 \%(\mathrm{w} / \mathrm{v})$ SDS in PBS for 5 and $10 \mathrm{~min}$, respectively, at room temperature. All antibody dilutions and washes were in PBS and nuclei were stained with $1 \mu \mathrm{g} / \mathrm{ml} \mathrm{DAPI}$. Cells were mounted in PermaFluor (Thermo Scientific, Scoresby, VIC, Australia). Images were collected by laser-scanning confocal microscopy using either a Leica TCS NT upright or Leica SP5 inverted confocal microscope, $\times 100$ oil lens (numerical aperture 1.4) and Leica LAS AF software (Leica Microsystems, Wetzlar, Germany). Images were processed using Imaris (version 7; Bitplane AG, Zurich, Switzerland) image processing and analysis software. Where indicated, threedimensional image stacks were deconvolved using AutoQuant X 2 (Media Cybernetics, Bethesda, MD, USA) software.

Colocalisation analysis was performed on individual cells using Imaris software. Briefly, separate volumes were defined for LROs (based on Lamp staining) and GrB by automatic thresholding based on absolute intensity. Overlap coefficients according to Manders, ${ }^{51}$ which range from 0 (no colocalisation) to $1(100 \%$ colocalisation) and represent the true degree of colocalisation, were determined.

TCR cross-linking induces rapid LRO exocytosis and release of a proportion of $\mathrm{GrB}$ and $\mathrm{Pf}$ into the medium. In some imaging experiments, to prevent release of GrB into the medium via degranulation and consequent loss of signal, activated cells were pretreated with $10 \mu \mathrm{M}$ nocodazole for $3 \mathrm{~h}$ (disrupts microtubules required for mobilisation of LROs) before con-A restimulation. Nocodazole was maintained throughout the experiment.

Time-lapse microscopy and image analyses. YT cells expressing GrB-eGFP were immobilised on glass coverslips coated with Cell-Tak and exposed to $250 \mu \mathrm{M}$ LLOMe in RPMl-10 buffered with $10 \mathrm{mM}$ HEPES, pH 7.2. Imaging was performed on a Perkin Elmer Ultraview LCI (Perkin Elmer, Waltham, MA, USA). This system included an Olympus IX70 invert microscope (Olympus Australia, Melbourne, VIC, Australia), equipped with a Yokogawa CSU10 spinning disk unit (Yokogawa Australasia, Macquarie Park, NSW, Australia), an UltraPix FSI 1000 cooled CCD camera (1280 $\times 1024$ pixels) (Perkin Elmer) and a triple line ArKr gas laser. Images were captured at $5 \mathrm{~min}$ intervals over a 2 -h period using a $\times 60$ lens and $2 \times 2$ binning of the camera. Non-adherent CLs were cultured in polydimethylsiloxane microgrids ${ }^{52}(125 \times 125 \mu \mathrm{m}$ by $60 \mu \mathrm{m}$ deep and containing 32 chambers) positioned in 8-well microslides (Ibidi, Munich, Germany). The microgrids have walls but no lid and act as corrals, physically confining a small number of cells in each chamber. CLs in medium supplemented with $25 \mathrm{mM} \mathrm{HEPES}, \mathrm{pH} 7.2$ (and $1.8 \mathrm{mM} \mathrm{CaCl}_{2}$ for AV binding) were seeded at a density that resulted in 0 5 cells per chamber. After the cells settled, medium containing LLOMe was added to give a final concentration of $250 \mu \mathrm{M}$. Where indicated, PI and FITC-AV (BD Biosciences) were added to the chambers as recommended by the manufacturer. In some experiments, cells were pretreated with $100 \mu \mathrm{M} \mathrm{C20}$ for $3 \mathrm{~h}$ before seeding in microgrids. Images were captured using Leica LAS AF software on Leica SP5 or Leica AF6000 LX microscopes fitted with humidified temperature and gas-controlled chambers. Differential interference contrast and fluorescence images were captured at time intervals of $2-5 \mathrm{~min}$ over $4-6 \mathrm{~h}$. All image analyses and manipulations were performed using Leica LAS AF Lite software and MetaMorph Imaging Series 7 software (Molecular Devices, Sunnyvale, CA, USA). The duration from addition of LLOMe to the first appearance of membrane blebbing, AV binding and PI uptake was recorded for individual cells.
NK cells were cultured with HeLa cells in PI-supplemented medium and images collected at 5 min intervals using an Olympus IX-81 microscope and MetaMorph software. Images were processed in MetaMorph.

Statistical analysis. In general, unpaired $t$-tests were used to analyse potential differences between experimental groups; the Mann-Whitney test was applied to colocalisation data. Statistical analyses were performed using GraphPad Prism 5.0 analysis software. Unless otherwise stated, results are expressed as mean \pm S.E.M. Differences were considered statistically significant if the $P$-value was 0.05 or less $\left({ }^{\star} P<0.05 ;{ }^{* \star} P<0.01 ;{ }^{* \star} P<0.001 ;{ }^{* \star \star *} P<0.0001\right)$.

\section{Conflict of Interest}

The authors declare no conflict of interest.

Acknowledgements. We thank V Sutton and O Susanto (Peter MacCallum Cancer Centre, Melbourne, VIC, Australia) for assistance with mouse CLs, J Trapani (Peter MacCallum Cancer Centre) for 2C5 and PB2 antibodies, and D Day (Centre for Micro-Photonics, Faculty of Engineering and Industrial Sciences, Swinburne University of Technology, Hawthorn, VIC, Australia) for provision of microgrids. This work was supported by the National Health and Medical Research Council (Australia). NJW and MJS were supported by a NH\&MRC Career Development Award and Australia Fellowship, respectively.

1. Snow AL, Pandiyan P, Zheng L, Krummey SM, Lenardo MJ. The power and the promise of restimulation-induced cell death in human immune diseases. Immunol Rev 2010; 236: 68-82.

2. Strasser A, Jost PJ, Nagata $S$. The many roles of FAS receptor signaling in the immune system. Immunity 2009; 30: 180-192.

3. Brenner D, Golks A, Becker M, Muller W, Frey CR, Novak R et al. Caspase-cleaved HPK1 induces CD95L-independent activation-induced cell death in T and B lymphocytes. Blood 2007; 110: 3968-3977.

4. Chhabra A, Mehrotra S, Chakraborty NG, Dorsky DI, Mukherji B. Activation-induced cell death of human melanoma specific cytotoxic $T$ lymphocytes is mediated by apoptosisinducing factor. Eur J Immunol 2006; 36: 3167-3174.

5. Ida H, Robertson MJ, Voss S, Ritz J, Anderson P. CD94 ligation induces apoptosis in a subset of IL-2-stimulated NK cells. J Immunol 1997; 159: 2154-2160.

6. Ida H, Nakashima T, Kedersha NL, Yamasaki S, Huang M, Izumi Y et al. Granzyme B leakage-induced cell death: a new type of activation-induced natural killer cell death. Eur J Immunol 2003; 33: 3284-3292.

7. Azzoni L, Anegon I, Calabretta B, Perussia B. Ligand binding to Fc gamma R induces c-myc-dependent apoptosis in IL-2-stimulated NK cells. J Immunol 1995; 154: 491-499.

8. Ortaldo JR, Mason AT, O'Shea JJ. Receptor-induced death in human natural killer cells: involvement of CD16. J Exp Med 1995; 181: 339-344.

9. Dell'Angelica EC, Mullins C, Caplan S, Bonifacino JS. Lysosome-related organelles. FASEB J 2000; 14: 1265-1278.

10. Peters PJ, Borst J, Oorschot V, Fukuda M, Krahenbuhl O, Tschopp J et al. Cytotoxic T lymphocyte granules are secretory lysosomes, containing both perforin and granzymes. J Exp Med 1991; 173: 1099-1109.

11. Anthony DA, Andrews DM, Watt SV, Trapani JA, Smyth MJ. Functional dissection of the granzyme family: cell death and inflammation. Immunol Rev 2010; 235: 73-92.

12. Kaiserman D, Bird CH, Sun J, Matthews A, Ung K, Whisstock JC et al. The major human and mouse granzymes are structurally and functionally divergent. J Cell Biol 2006; 175: 619-630.

13. Kaiserman D, Bird PI. Control of granzymes by serpins. Cell Death Differ 2010; 17: 586-595.

14. Bird CH, Sutton VR, Sun J, Hirst CE, Novak A, Kumar S et al. Selective regulation of apoptosis: the cytotoxic lymphocyte serpin proteinase inhibitor 9 protects against granzyme B-mediated apoptosis without perturbing the Fas cell death pathway. Mol Cell Biol 1998; 18: $6387-6398$.

15. Hirst CE, Buzza MS, Bird CH, Warren HS, Cameron PU, Zhang M et al. The intracellular granzyme $B$ inhibitor, proteinase inhibitor 9 , is up-regulated during accessory cell maturation and effector cell degranulation, and its overexpression enhances CTL potency. $J$ Immunol 2003; 170: 805-815.

16. Bird CH, Blink EJ, Hirst CE, Buzza MS, Steele PM, Sun J et al. Nucleocytoplasmic distribution of the ovalbumin serpin PI-9 requires a nonconventional nuclear import pathway and the export factor Crm1. Mol Cell Biol 2001; 21: 5396-5407.

17. Zhang M, Park SM, Wang Y, Shah R, Liu N, Murmann AE et al. Serine protease inhibitor 6 protects cytotoxic $T$ cells from self-inflicted injury by ensuring the integrity of cytotoxic granules. Immunity 2006; 24: 451-461.

18. Devadas S, Das J, Liu C, Zhang L, Roberts Al, Pan Z et al. Granzyme B is critical for $T$ cell receptor-induced cell death of type 2 helper T cells. Immunity 2006; 25: 237-247. 
19. Laforge M, Bidere N, Carmona S, Devocelle A, Charpentier B, Senik A. Apoptotic death concurrent with $\mathrm{CD} 3$ stimulation in primary human $\mathrm{CD} 8+\mathrm{T}$ lymphocytes: a role for endogenous granzyme B. J Immunol 2006; 176: 3966-3977.

20. Sharma V, Delgado M, Ganea D. Granzyme B, a new player in activation-induced cell death, is down-regulated by vasoactive intestinal peptide in Th2 but not Th1 effectors $\mathrm{J}$ Immunol 2006; 176: 97-110.

21. Mateo V, Menager M, de Saint-Basile G, Stolzenberg MC, Roquelaure B, Andre N et al Perforin-dependent apoptosis functionally compensates Fas deficiency in activationinduced cell death of human T lymphocytes. Blood 2007; 110: 4285-4292.

22. Turk B, Turk V. Lysosomes as 'suicide bags' in cell death: myth or reality? J Biol Chem 2009; 284: 21783-21787.

23. Johansson AC, Appelqvist H, Nilsson C, Kagedal K, Roberg K, Ollinger K. Regulation of apoptosis-associated lysosomal membrane permeabilization. Apoptosis 2010; 15 527-540.

24. Willoughby CA, Bull HG, Garcia-Calvo M, Jiang J, Chapman KT, Thornberry NA. Discovery of potent, selective human granzyme $B$ inhibitors that inhibit CTL mediated apoptosis. Bioorg Med Chem Lett 2002; 12: 2197-2200.

25. Trapani Joseph A, Browne KA, Smyth MJ, Jans DA. Localization of granzyme B in the nucleus: a putative role in the mechanism of cytotoxic lymphocyte-mediated apoptosis. J Biol Chem 1996; 271: 4127-4133.

26. Droga-Mazovec G, Bojic L, Petelin A, Ivanova S, Romih R, Repnik U et al. Cysteine cathepsins trigger caspase-dependent cell death through cleavage of bid and antiapoptotic Bcl-2 homologues. J Biol Chem 2008; 283: 19140-19150.

27. Kagedal K, Zhao M, Svensson I, Brunk UT. Sphingosine-induced apoptosis is dependent on lysosomal proteases. Biochem J 2001; 359: 335-343.

28. Bird CH, Rizzitelli A, Harper I, Prescott M, Bird PI. Use of granzyme B-based fluorescent protein reporters to monitor granzyme distribution and granule integrity in live cells. Biol Chem 2010; 391: 999-1004

29. Kelly JM, Waterhouse NJ, Cretney E, Browne KA, Ellis S, Trapani JA et al. Granzyme M mediates a novel form of perforin-dependent cell death. J Biol Chem 2004; 279 22236-22242.

30. Warren HS. Target-induced natural killer cell loss as a measure of NK cell responses J Immunol Methods 2011; 370: 86-92.

31. Jewett A, Bonavida B. Target-induced inactivation and cell death by apoptosis in a subset of human NK cells. J Immunol 1996; 156: 907-915.

32. Taga K, Yamauchi A, Kabashima K, Bloom ET, Muller J, Tosato G. Target-induced death by apoptosis in human lymphokine-activated natural killer cells. Blood 1996; 87: 2411-2418.

33. Yamauchi A, Taga K, Mostowski HS, Bloom ET. Target cell-induced apoptosis of interleukin-2-activated human natural killer cells: roles of cell surface molecules and intracellular events. Blood 1996; 87: 5127-5135.

34. Opferman JT, Ober BT, Narayanan R, Ashton-Rickardt PG. Suicide induced by cytolytic activity controls the differentiation of memory CD8 $(+)$ T lymphocytes. Int Immunol 2001; 13: $411-419$.

35. Thurston TL, Wandel MP, von Muhlinen N, Foeglein A, Randow F. Galectin 8 targets damaged vesicles for autophagy to defend cells against bacterial invasion. Nature 2012; 482: 414-418.
36. Paz I, Sachse M, Dupont N, Mounier J, Cederfur C, Enninga J et al. Galectin-3, a marker for vacuole lysis by invasive pathogens. Cell Microbiol 2010; 12: 530-544.

37. Burshtyn DN. NK cells and poxvirus infection. Front Immunol 2013; 4: 7.

38. Parker AK, Parker S, Yokoyama WM, Corbett JA, Buller RML. Induction of natural killer cell responses by ectromelia virus controls infection. J Virol 2007; 81: 4070-4079.

39. Bhat R, Watzl C. Serial killing of tumor cells by human natural killer cells-enhancement by therapeutic antibodies. PLOS One 2007; 2: e326.

40. Rothstein TL, Mage M, Jones G, McHugh LL. Cytotoxic T lymphocyte sequential killing of immobilized allogeneic tumor target cells measured by time-lapse microcinematography. J Immunol 1978; 121: 1652-1656.

41. Azzi J, Skartsis N, Mounayar M, Magee CN, Batal I, Ting C et al. Serine protease inhibitor 6 plays a critical role in protecting murine granzyme B-producing regulatory $\mathrm{T}$ cells. J Immunol 2013; 191: 2319-2327.

42. Jahrsdorfer B, Blackwell SE, Wooldridge JE, Huang J, Andreski MW, Jacobus LS et al. B-chronic lymphocytic leukemia cells and other B cells can produce granzyme B and gain cytotoxic potential after interleukin-21-based activation. Blood 2006; 108 : 2712-2719.

43. Regner M, Mullbacher A. Granzymes in cytolytic lymphocytes-to kill a killer? Immunol Cell Biol 2004; 82: 161-169.

44. Crozat K, Hoebe K, Ugolini S, Hong NA, Janssen E, Rutschmann S et al. Jinx, an MCMV susceptibility phenotype caused by disruption of Unc13d: a mouse model of type 3 familial hemophagocytic lymphohistiocytosis. J Exp Med 2007; 204: 853-863.

45. Sun J, Bird CH, Sutton V, McDonald L, Coughlin PB, De Jong TA et al. A cytosolic granzyme $B$ inhibitor related to the viral apoptotic regulator cytokine response modifier $A$ is present in cytotoxic lymphocytes. J Biol Chem 1996; 271: 27802-27809.

46. Zhang M, Liu N, Park SM, Wang Y, Byrne S, Murmann AE et al. Serine protease inhibitor 6-deficient mice have increased neutrophil immunity to Pseudomonas aeruginosa. J Immunol 2007; 179: 4390-4396

47. Hirst CE, Buzza MS, Sutton VR, Trapani JA, Loveland KL, Bird PI. Perforin-independent expression of granzyme $B$ and proteinase inhibitor 9 in human testis and placenta suggests a role for granzyme B-mediated proteolysis in reproduction. Mol Hum Reprod 2001; 7: 1133-1142.

48. Geisberg M, Trapani JA, Dupont B. Monoclonal antibodies detecting discrete epitopes of human perforin. Tissue Antigens 1990; 35: 229-233.

49. Trapani JA, Browne KA, Dawson M, Smyth MJ. Immunopurification of functional Asp-ase (natural killer cell granzyme B) using a monoclonal antibody. Biochem Biophys Res Commun 1993; 195: 910-920.

50. Sayers TJ, Brooks AD, Ward JM, Hoshino T, Bere WE, Wiegand GW et al. The restricted expression of granzyme M in human lymphocytes. J Immunol 2001; 166: 765-771.

51. Zinchuk V, Zinchuk O, Okada T. Quantitative colocalization analysis of multicolor confocal immunofluorescence microscopy images: pushing pixels to explore biological phenomena. Acta Histochem Cytochem 2007; 40: 101-111.

52. Day D, Pham K, Ludford-Menting MJ, Oliaro J, Izon D, Russell SM et al. A method for prolonged imaging of motile lymphocytes. Immunol Cell Biol 2009; 87: $154-158$

\section{Supplementary Information accompanies this paper on Cell Death and Differentiation website (http://www.nature.com/cdd)}

